\title{
Does your health care depend on how your insurer pays providers? Variation in utilization and outcomes in Thailand
}

\author{
Sanita Hirunrassamee • Sauwakon Ratanawijitrasin
}

Received: 7 March 2009 / Accepted: 21 March 2009 / Published online: 26 April 2009

(C) The Author(s) 2009. This article is published with open access at Springerlink.com

\begin{abstract}
Hospitals in Thailand operate in a multiple insurance payment environment. This paper examines (1) access to medicines and other medical technologies, (2) treatment outcomes, and (3) efficiency in resource use, among beneficiaries of the three government health insurance schemes in Thailand. Using 2003-2005 outpatient and inpatient data for patients with three tracer diseases from three government hospitals, we find that utilization of more expensive items differs between patients whose insurers pay on a closed- or openended basis. Where new vs. conventional drugs are both available, patients whose insurer pays on a fee-for-service basis tend to have greater access to new drugs, compared to patients whose insurer pays on a capitated or case basis. Similar patterns were found where there are options between originator versus generic drugs, drugs in different dosage forms, and more versus less advanced diagnostic technologies. Effects of insurance payment are more pronounced where price gaps among the medical technologies are significant. Efficiency results are mixed, depending on nature of the disease conditions and type of resources required for treatment.
\end{abstract}

Keywords Health insurance $\cdot$ Payment methods - Drug utilization · Access $\cdot$ Efficient healthcare treatment

\section{JEL Classification I10}

\section{Introduction}

For the majority of the uninsured, the Thai government's introduction of the 30 Baht Health Care Scheme in 2001 substantially changed access to health services. The scheme also

\footnotetext{
S. Hirunrassamee $(\bowtie)$

Faculty of Pharmaceutical Sciences, Chulalongkorn University, Bangkok, Thailand e-mail: sanita_h@yahoo.com

S. Ratanawijitrasin

Faculty of Social Sciences and Humanities, Mahidol University, Bangkok, Thailand
} 
changed the way most hospitals are reimbursed for services. The new 30 Baht Scheme was initiated to provide coverage to all citizens not eligible for any other public sector health insurance program, and thus moved Thailand toward its goal of universal health coverage. The 30 Baht Scheme, which is the largest insurance program in the country, covers approximately 48.4 million people, or $76.6 \%$ of the population (National Statistics Bureau 2007). The scheme is funded entirely by general taxes. It pays hospital outpatient services based on the number of registered patients. For inpatient services, the diagnostic-related group (DRG) method is used. Payment for drugs is included in the per-person and DRG rates. In addition, the scheme also pays per item for a small number of high-cost diseases.

The 30 Baht Scheme operates alongside two other major public schemes of health security: the Social Security Scheme (SSS) and Civil Service Medical Benefits Scheme (CSMBS).

The SSS covers private business employees, which number about 8 million. It is financed by equal contributions from employees, employers, and the government. Payment to contracted hospitals is made on a capitation basis and covers outpatient and inpatient services. Additional utilization-related payments, with ceilings, are made for a limited number of diseases.

The CSMBS is a government fringe benefit package that pays for health services used by government employees and their dependents. Beneficiaries number about 6 million people. The scheme is financed by taxes. Previously, the CSMBS paid both outpatient and inpatient services on a fee-for-service basis. After a multiyear attempt to change the payment rules, the DRG method was effectively instituted for paying inpatient services in 2007. Outpatient drugs are now paid per item and outpatient services per service, while the costs of inpatient drugs are included in the DRG payment.

A large number of people buy private insurance to either supplement or supplant the benefits of the public programs they are eligible to join. Approximately 1.5 million people have private health insurance benefits. Since private health insurance is voluntary, those who choose to enroll pay a premium to insurance companies. Such companies generally pay on a fee-for-service basis. This means that pharmaceuticals are paid per item (Ratanawijitrasin 2005).

Since Thai hospitals were long paid on a fee-for-service basis, the introduction of the 30 Baht Scheme caused a major shift in the hospital environment; now, services to the largest segment of the population are paid on a closed-end basis (as defined by Jegers et al. 2002). Currently, private health insurance and CSMBS outpatient services are reimbursed by service. Because the three major public health insurance systems and private health insurance employ different methods to pay for health services, hospitals in Thailand confront a mix of financial incentives when managing their service provision.

Almost all hospitals provide services to the beneficiaries of these different insurance systems. Facing multiple payment incentives, many hospitals set prescribing and dispensing guidelines that differ by insurance scheme. These commonly include cost-control mechanisms for certain services delivered on a closed-end basis. Examples of such restrictions include: "Prescribe only medicines listed in the National Essential Drug List (NEDL) to patients in the capitation payment group, "No prescription of "medicine X' for capitation patients," "Substitute generic drugs for capitation patients," "Dispense only a three-day supply of drugs when discharging patients under any case-based payment system," and "Hospital director's approval needed before using MRI for 30 Baht patients." Hence, servicesincluding the prescription of medicine-might differ across insurance systems, even for patients with the same condition.

Such rules are the behavioral response of health providers operating under multiple health insurance plans with differing payment incentives. Unfortunately, aside from anecdotal 
accounts of how some hospitals have tried to influence resource utilization, no systematic survey has documented the type and extent of these hospital policies and rules.

Closed-end payments seek to provide financial incentives for health care providers to deliver services more efficiently. How payment incentives actually influence efficiency, and how they affect service utilization, have been issues of debate in health policy. A large number of empirical studies in different countries show that financial incentives associated with open-end payment methods lead to more health service utilization — both in terms of quantity and type-while closed-end payment methods lead to less utilization. Reviews of studies on the effects of health insurance financial incentives find that most compare certain utilization variables across diseases and patients. A few are same-disease studies, which allow more specific evaluation of patients who need comparable care. Few studies focus on health outcomes (Chaix-Couturier et al. 2000; Petersen et al. 2006; McCall et al. 2003).

In Thailand, recent reform has changed the environment in which hospitals operate. Whether and how this change affects the use of health resources at the macro and micro levels, as well as what health outcomes it has produced, are important policy questions. So far, only a few studies provide empirical evidence on this issue, and none evaluate health outcomes.

This article sets out to examine resource utilization patterns and health outcomes under the multiple payment methods in Thailand. It focuses on assessing (1) access to medicines and other medical technologies, (2) treatment outcomes, and (3) efficiency in resource use among beneficiaries of the three government health insurance schemes in Thailand.

\section{Methodology}

This study employs a same-disease approach to compare health service utilization and outcomes based on clinical practice guidelines. Three tracer conditions are used to capture utilization patterns across a range of payment methods and points of service. Hospital data between fiscal years 2003 and 2005 derive from electronic databases and paper medical records.

\section{Range of provider payment methods}

Because of the changes in payment methods over the years, we first describe the specific methods employed by each system during the study timeframe. For the time period covered by this study, CSMBS paid on a fee-for-service basis for both outpatient and inpatient services. The use of the DRG method for inpatient services, without overall budget limits, was announced in 2001 and officially implemented in July 2007.

The 30 Baht Scheme calculates a budget for paying medical services per person, per year. The overall capitation rate is then deducted for categories of payment such as inpatient, emergency care, prevention, promotion, a administration costs for the center and provincial agencies (and percentage of personnel salaries for government hospitals)—before disbursement to providers. The per-person payment rate to government hospitals varies by hospital. The overall rate per person, before deductions, was 1,308 Baht (approximately \$37) in 2004. Several payment methods, all closed-end, were employed:

1. A capitation rate for outpatient services In 2004 , the mid-point of the study period, each of the three hospitals in the study received a different amount per person per year for outpatient services: 510 Baht (approximately \$15), 484 Baht (\$14), and 450 Baht (\$13). 
2. A per-item payment for outpatient treatment of a limited number of high-cost diseases In 2003 the scheme paid per item per year, with a ceiling of 30,000 Baht per person per year (approximately \$857) for cancer. In 2004-2005 this was changed to per item per visit, with a ceiling of 4,000 Baht per visit (approximately \$114).

3. DRGs with a global budget for inpatient services.

SSS also uses closed-end payment methods. It pays capitation for all outpatient and inpatient services (at the same rate for all hospitals). In addition, it also pays per item per year, with a ceiling for the treatment of certain high-cost diseases in both outpatient and inpatient cases.

\section{Tracer conditions}

In order to compare the different health insurance schemes, we evaluated specific utilization rates and outcomes at the disease level using tracer conditions. A disease condition to be selected as tracer for this study must satisfy the following requirements:

1. The disease conditions are commonly found in hospitals in Thailand.

2. The disease conditions require drug therapy.

3. The disease conditions reflect the type of payment categories and point of service under study.

- Payment categories general and high cost/catastrophic diseases.

- Point of service outpatient visit only, inpatient admission only, and both outpatient and inpatient visits.

4. The disease conditions must be classified within the system of International Classification of Diseases — version 10 (ICD-10)—so that their data are retrievable from hospitals' computerized information systems and are comparable.

5. Because medical records for many disease conditions lack detailed diagnosis and treatment information, which makes assessment impossible, this study requires that the disease conditions must have the relevant outcome and cost data available.

6. The disease conditions can be clearly diagnosed and do not have complicated patterns of comorbidity. This is to simplify the process of outcome assessment.

Three disease conditions were identified for this study. They are acute upper gastrointestinal bleeding (AUGIB), epilepsy, and lung cancer.

AUGIB can be clearly diagnosed, has clear clinical guidelines, and requires inpatient admission and a short duration of treatment. This condition is classified as a general disease in the payment systems. Only inpatient admission cases were studied.

Epilepsy can also be clearly diagnosed, requires drug therapy, and has the clear treatment goal of helping patients become seizure free. Patients suffering from epilepsy need long-term care, which normally includes both outpatient and inpatient services. Epilepsy also belongs to the general disease category for payment.

Lung cancer patients in the early stages of the disease (stages 1 and 2) are treated using surgery, radioactive therapy, and chemotherapy. In this study, all lung cancer patients treated by chemotherapy (drug treatment) were selected for the study on access to drugs. For the efficiency evaluation, because unambiguous outcome data were needed, we selected only those patients with non-small cell lung cancer in stages 3 and 4 whose treatment option is limited to drug therapy. A patient in these two stages has a median survival of no more than 29 months, with an average of approximately 12 months depending on the choice of drug regimen. This tracer is a high-cost disease (Table 1 ). 


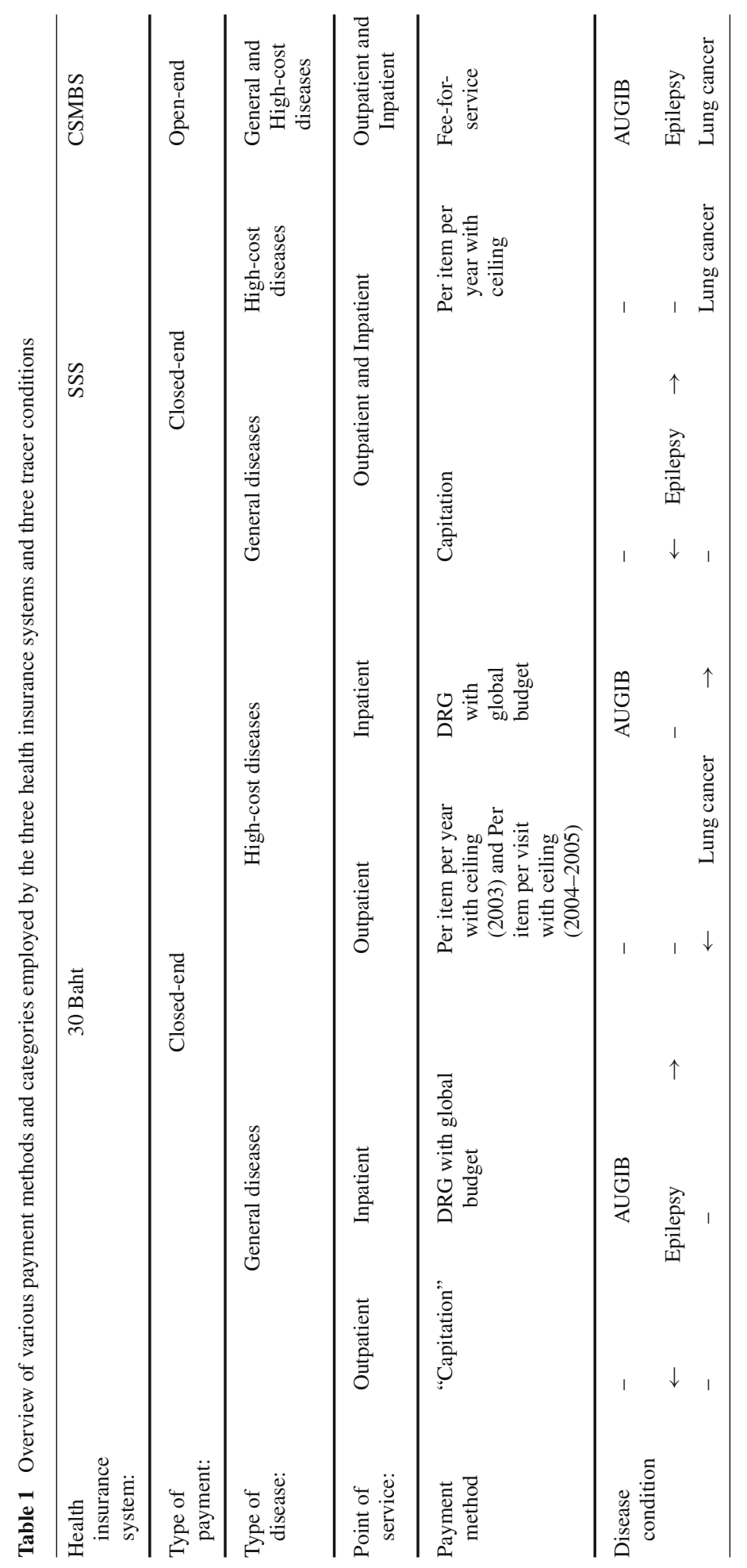


Standards for diagnosis and drug therapy

Standard treatment guidelines issued by relevant professional societies were used for evaluating practice patterns. This study focused on the key recommendations for required minimum standards of care for each tracer condition. The recommendations are provided below.

1. AUGIB Clinical guidelines (Gastroenterological Association of Thailand 2004) require that diagnosis be determined by gastroscopic imaging and inpatient admission; the drug of choice is any proton pump inhibitor (PPI).

2. Epilepsy Anti-epileptic drugs are adjusted to achieve the goal of being seizure free. Clinical guidelines (Epilepsy Society of Thailand 2004) indicate the use of an anti-epileptic drug appropriate for treatment. Conventional anti-epileptic drugs, although effective, usually cause serious adverse drug reactions (ADRs). Newer drugs offer better efficacy and fewer side effects, but cost more.

3. Lung cancer (National Cancer of Thailand and Department of Medical Service 2005) The disease can be definitively diagnosed using computerized tomographic (CT) scanning or magnetic resonance imaging (MRI). Drug treatment regimens can be chosen from various combinations of anti-neoplastic drugs.

New generation anti-neoplastic drugs, which are more expensive, are also more effective in stemming symptoms and aiding patient survival.

Patients treated with anti-neoplastic drugs, both old and new, suffer from severe side effects such as nausea, vomiting, and anemia. To lessen these side effects, palliative drugs such as anti-emetics and granulocyte colony stimulating factors (G-CSF) can be considered for the management of ADRs. The costs of these drugs, particularly G-CSF, are high.

\section{Treatment outcomes}

Standard treatment guidelines issued by the relevant authorities were used as the basis for evaluating desired outcomes. Key measurable outcome variables used in the evaluation for the tracer diseases are as follows:

1. AUGIB The desired outcome, or cure, is defined as complete stoppage of bleeding. Information on the bleeding condition was indicated in the gastroscope results and medical records. Outcomes were determined at the point of discharge.

2. Epilepsy Becoming seizure free is the desired outcome of epilepsy treatment. In this study, a patient is considered seizure free if, from the medical record, he or she had no seizure symptoms in the past year.

3. Lung cancer Two criteria determine whether desired treatment outcomes of lung cancer were achieved in this study: (a) the patient responded to anti-neoplastic treatment- that is, there was no metastasis to other organs, such as the brain or liver, after the completion of anti-neoplastic treatments; and (b) the patient survived at least one year after the anti-neoplastic treatments. Drop-out cases were excluded from the analysis.

\section{Drug costs}

Each hospital purchased its own medicines and set its own service charges. Therefore, the costs of drugs and services differ by hospital. In this study, the charges of the largest of the three hospitals were used as a reference point for calculation. Procurement costs were identified for each individual drug product with the same brand and generic name, dosage form, 
Table 2 Relevant drugs for the tracer conditions included in the analysis

\begin{tabular}{|c|c|c|}
\hline AUGIB & Epilepsy & Lung cancer \\
\hline $\begin{array}{l}\text { 1. Alimentary drugs } \\
\text { - Proton pump inhibitor } \\
\text { - Antacid } \\
\text { - H2 blocker } \\
\text { - Others, e.g., antispasmodics } \\
\text { 2. Intravenous and other } \\
\text { sterile solutions } \\
\text { - IV fluid } \\
\text { - Colloidal plasma volume } \\
\text { substitute } \\
\text { 3. Haemostatic drugs } \\
\text { - Sandostatin } \\
\text { - Vitamin K } \\
\text { - Factor VII } \\
\text { - Factor VIII } \\
\text { - Tranxenamic acid }\end{array}$ & $\begin{array}{l}\text { 1. Conventional } \\
\text { antiepileptic drugs: e.g., } \\
\text { phenobarbital, phenytoin, } \\
\text { sodium valproate } \\
\text { 2. New antiepileptic drugs: } \\
\text { e.g., lamotrigine, } \\
\text { topiramate }\end{array}$ & $\begin{array}{l}\text { 1. Conventional antineoplastic } \\
\text { drugs: e.g., cisplatin, } \\
\text { doxorubicin } \\
\text { 2. New antineoplastic drugs: } \\
\text { e.g., gemtarabine } \\
\text { 3. Anti-emetic drugs: e.g., } \\
\text { ondansetron } \\
\text { 4. Granulocyte } \\
\text { colony-stimulating factor } \\
\text { (G-CSF): e.g., granocyte } \\
\text { 5. Antimicrobial drugs }\end{array}$ \\
\hline
\end{tabular}

and strength. For services, since cost figures were unavailable, a charge for each individual procedure was used.

Total drug costs per case were defined as costs of all required drugs given during the duration of treatment, as detailed below.

1. AUGIB A patient with AUGIB arrives in a hospital emergency room (ER) and is then admitted as an inpatient. The duration of treatment is defined as the time from the first hospital contact for that episode till the time of discharge.

Any of the drugs used in the treatment of this particular condition was included. Relevant drugs are categorized in Table 2. Drugs given for purposes other than the treatment of AUGIB were excluded from the calculation. Total drug costs per case consist of drugs used for the entire episode, from the first hospital contact point - the ER-till discharge, including take-home medications.

2. Epilepsy Since the key outcome is being seizure free for an entire year, the duration of treatment for epilepsy was defined as a fiscal year-October 1-September 30. Relevant drugs for this condition are anti-epileptic drugs.

3. Lung cancer Relevant drugs used in the cost calculation are listed in Table 2.

Data sources

Study sites

Data were collected from three government hospitals. The first is a medical school in the capital, Bangkok, with a 1,200-bed capacity. The second is a large general hospital (provincial level) with a 500-bed capacity. The third is a general hospital in a different province with a 200-bed capacity. The two latter hospitals are located in two separate provinces in the northeastern region of Thailand. 


\section{Electronic databases}

Hospital electronic diagnosis and drug dispensing databases were used as data sources. The records were available on an individual patient level. Data from the entire patient populations of the three hospitals, which satisfied the inclusion criteria, from three fiscal years-October 1, 2002, to September 30, 2005-were retrieved for this study.

The data include patient demographics, health insurance benefits, items and costs of prescribed drugs, and treatment procedures.

\section{Paper medical records}

Information on patient outcomes was not available from the computerized hospital information system. Medical records in paper form were the only data source for such information. Using patient hospital numbers from the electronic databases, samples of paper medical records were drawn for the analysis.

Inclusion and exclusion criteria

\section{Inclusion criteria}

Included in the study were patients who had: (1) been diagnosed as having the tracer disease, according to the pertinent ICD10; (2) visited or admitted to any of the three hospitals under study between October 1, 2002, and September 30, 2005; and (3) received relevant drug therapy for the tracer disease.

An epileptic patient must have been treated with anti-epileptic drugs for no less than 90 consecutive days (to qualify as suffering epilepsy as a chronic condition rather than an occasional one). An AUGIB patient must have been admitted to the hospital as an inpatient.

\section{Exclusion criteria}

Data of patients with the following attributes were excluded from the study.

1. Patients who were covered by more than one health insurance benefit scheme between October 1, 2002, and September 30, 2005 were excluded. This means, for example, that beneficiaries of one government health insurance system who also bought private health insurance, and those who switched from SSS coverage to the 30 Baht Scheme due to job loss were excluded.

2. Patients whose medical records did not contain complete clinical outcome data for evaluation.

3. For patients with epilepsy, transaction data of hospital visits with anti-epileptic drugs less than 90 consecutive days, and patients diagnosed as purely status epilepticus or who had obtained only anti-epileptic injection drugs (likely to be acute cases), were excluded.

The protocols for selecting transaction data of each of the three tracer diseases are schematized in Fig 1. 


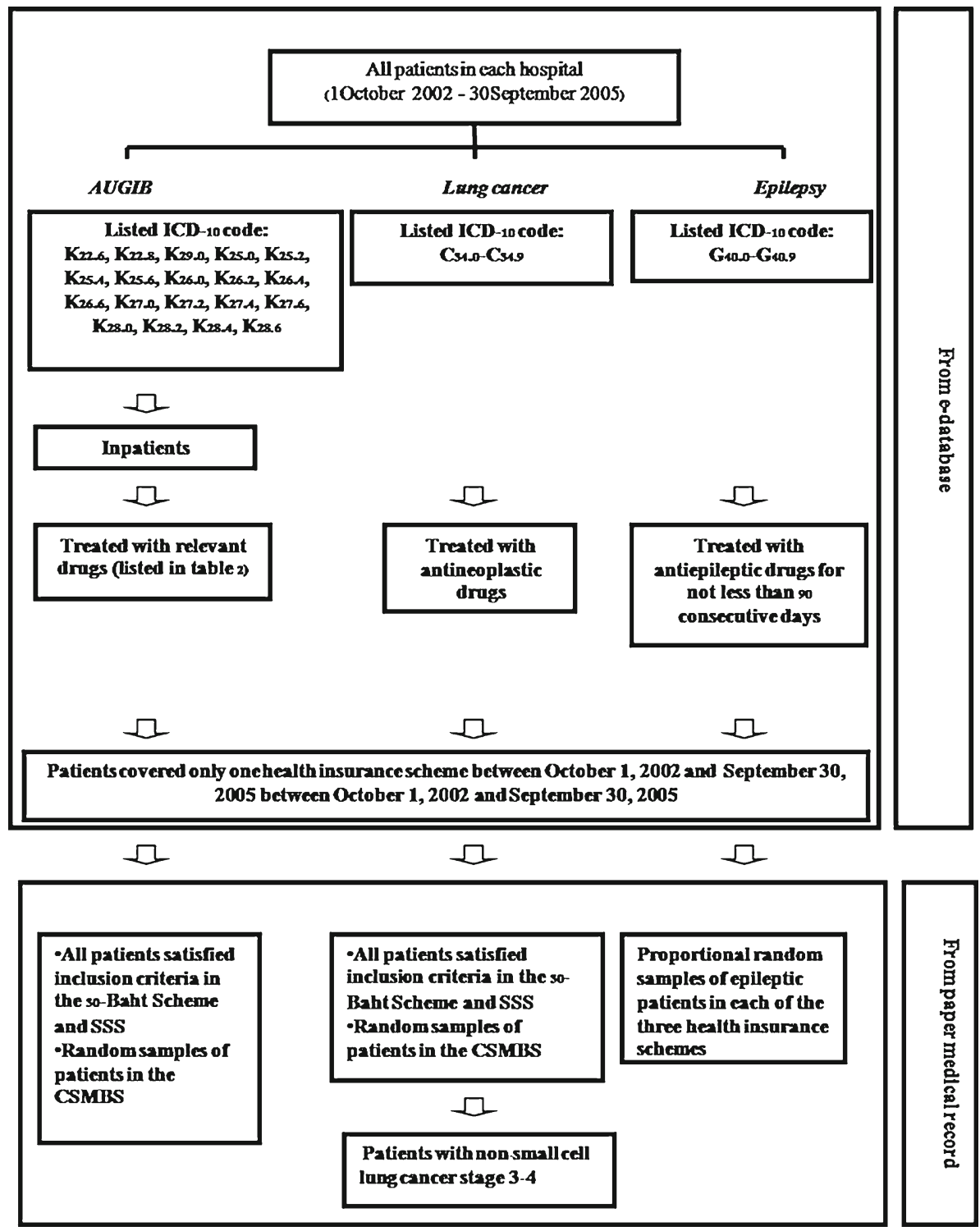

Fig. 1 Steps taken in the selection of transaction data for tracer diseases

Population and samples

In Fig 1, the selection steps in the first box, dealing with electronic patient databases, yield transaction data for patients who satisfied the inclusion criteria. Cases selected in this group were used to analyze access to drugs and services.

Evaluation of treatment effects relied on outcome data retrieved from paper medical records. For AUGIB and non-small cell lung cancer, because of the smaller number of qualified cases in the 30 Baht Scheme and the SSS, medical records for all cases identified in the electronic database were retrieved; random samples of CSMBS cases were drawn using 
Table 3 Number of cases used in the analysis

\begin{tabular}{|c|c|c|c|c|c|}
\hline Tracer & Number of patients & $\begin{array}{l}30 \text { Baht } \\
\text { Scheme }\end{array}$ & SSS & CSMBS & Total \\
\hline \multirow[t]{2}{*}{ AUGB } & $\begin{array}{l}\text { Number of cases from } \\
\text { e-database }\end{array}$ & 41 & 18 & 320 & 379 \\
\hline & $\begin{array}{l}\text { Number of cases with } \\
\text { complete outcome data }\end{array}$ & 29 & 13 & $160^{*}$ & 206 \\
\hline \multirow[t]{2}{*}{ Epilepsy } & $\begin{array}{l}\text { Number of cases from } \\
\text { e-database }\end{array}$ & 116 & 68 & 729 & 913 \\
\hline & $\begin{array}{l}\text { Number of cases with } \\
\text { complete outcome data }\end{array}$ & $89 *$ & $62 *$ & $288^{*}$ & 439 \\
\hline \multirow[t]{3}{*}{ Lung cancer } & $\begin{array}{l}\text { Number of lung cancer } \\
\text { patients from e-database }\end{array}$ & 42 & 31 & 260 & 333 \\
\hline & $\begin{array}{l}\text { Number of non-small cell } \\
\text { lung cancer patients } \\
\text { (stage 3-4) from paper } \\
\text { medical records }\end{array}$ & 21 & 7 & $102 *$ & 130 \\
\hline & $\begin{array}{l}\text { Number of non-small cell } \\
\text { lung cancer patients } \\
\text { (stage 3-4) with } \\
\text { complete outcome data }\end{array}$ & 17 & 5 & 67 & 89 \\
\hline
\end{tabular}

Note: * Random samples

Krejcie and Morgan's (1970) table. For epilepsy, samples were drawn from cases in all three health insurance systems using the proportional random sampling method. Sample size was based on Krejcie and Morgan (1970). These cases were then checked for outcome data, and those with the required level of completion were used in the study.

Analysis

Drug and service utilization patterns were examined to compare access to certain medical technologies and the efficiency of resource use among the beneficiaries of the three government health insurance systems. The analysis of access to medical technologies focuses on the use of new drugs, palliative drugs, drugs in oral versus injectable forms, originator versus generic products, and high-cost diagnostic procedures, following the practice procedures for each of the tracers. Efficiency of resource utilization was compared using a cost-effectiveness evaluation.

Utilizations and outcomes were analyzed using Chi-Square, with Monte Carlo correction for cells having a value lower than 5. Difference of costs among the three groups were tested using one-way analysis of variance (ANOVA).

\section{Results}

The number of cases included in the analysis, according to the selection criteria, is summarized in Table 3. Records of patients in the electronic databases were used to assess access to medical technologies, including drugs. Paper medical records with complete outcome data, as required, were used to evaluate resource utilization efficiency and the corresponding electronic records. Note that we made use of lung cancer cases in the access analysis, and non-small cell lung cancer cases in the efficiency analysis. 
Table 4 Utilization of required drugs in AUGIB

\begin{tabular}{|c|c|c|c|c|c|c|}
\hline \multirow[t]{2}{*}{ Tracer disease } & \multicolumn{2}{|c|}{ Access to } & \multicolumn{3}{|c|}{ Health insurance payment methods } & \multirow{2}{*}{$\begin{array}{l}\text { Results } \\
p \text { value }\end{array}$} \\
\hline & & & $\begin{array}{l}30 \text { Baht } \\
\text { Scheme (\%) }\end{array}$ & SSS (\%) & CSMBS $(\%)$ & \\
\hline \multirow[t]{4}{*}{ AUGIB } & \multirow{4}{*}{$\begin{array}{l}\text { Required } \\
\text { drug }\end{array}$} & PPIs & $41(100)$ & $18(100)$ & $319(99.69)$ & 0.912 \\
\hline & & $\begin{array}{l}\text { PPIs (oral } \\
\text { form) }\end{array}$ & $36(87.80)$ & $17(94.44)$ & $296(92.50)$ & 0.537 \\
\hline & & $\begin{array}{l}\text { PPIs } \\
\text { (injectable } \\
\text { form) }\end{array}$ & $21(51.22)$ & $12(70.59)$ & $266(83.13)$ & 0.000 \\
\hline & & $\begin{array}{l}\text { Originator's } \\
\text { PPIs }\end{array}$ & $22(53.66)$ & $12(70.59)$ & $271(85.49)$ & 0.000 \\
\hline
\end{tabular}

Table 5 Access to new drugs and palliative drugs in epilepsy and lung cancer

\begin{tabular}{|c|c|c|c|c|c|c|}
\hline \multirow[t]{2}{*}{ Tracer disease } & \multicolumn{2}{|c|}{ Access to } & \multicolumn{3}{|c|}{ Health insurance payment methods } & \multirow{2}{*}{$\begin{array}{l}\text { Results } \\
p \text { value }\end{array}$} \\
\hline & & & $\begin{array}{l}30 \text { Baht } \\
\text { Scheme }(\%)\end{array}$ & $\operatorname{SSS}(\%)$ & CSMBS $(\%)$ & \\
\hline \multirow[t]{2}{*}{ Epilepsy } & New drug & $\begin{array}{l}\text { Anti-epileptic } \\
\text { drug }\end{array}$ & $15(12.93)$ & $13(19.12)$ & $224(30.73)$ & 0.000 \\
\hline & & $\begin{array}{l}\text { Anti-epileptic } \\
\text { drug paid out-of } \\
\text { pocket }\end{array}$ & $14(93.33)$ & $9(69.23)$ & $0(0)$ & - \\
\hline \multirow[t]{2}{*}{ Lung cancer } & New dry & $\begin{array}{l}\text { Anti-neoplastic } \\
\text { drug }\end{array}$ & $8(19.05)$ & $3(9.68)$ & $174(66.92)$ & 0.000 \\
\hline & & $\begin{array}{l}\text { Anti-neoplastic } \\
\text { drug paid out-of } \\
\text { pocket }\end{array}$ & $5(62.50)$ & $0(0)$ & $0(0)$ & - \\
\hline \multirow[t]{3}{*}{ Lung cancer } & Palliative drug & Anti-emetic drug & $38(90.48)$ & $27(87.10)$ & $235(90.38)$ & 0.329 \\
\hline & & $\begin{array}{l}\text { Originator's } \\
\text { anti-emetic drug }\end{array}$ & $3(7.14)$ & $2(6.45)$ & $154(59.23)$ & 0.000 \\
\hline & & G-CSF & $0(0)$ & $4(12.90)$ & $30(11.54)$ & 0.073 \\
\hline
\end{tabular}

Access to medical technologies

\section{Required drugs}

As shown in Table 4, there is no difference among the three health insurance systems in the case of patients suffering AUGB; a PPI is the required drug, according to clinical practice guideline. But CSMBS patients are more likely to receive the drug in injection form, as well as originator products, than patients in the closed-end schemes.

\section{New drugs}

The percentages of epileptic and lung cancer patients prescribed new drugs differ significantly across the health insurance schemes (Table 5). Patients in the closed-end payment schemes were less likely to receive new drugs than those in the open-end scheme. Only $13 \%$ of patients in the 30 Baht Scheme and 19\% in the SSS received new drugs, while $31 \%$ of those in the open-ended CSMBS received new drugs for treatment. For lung cancer treatment, the 
Table 6 Access to required diagnostic procedures

\begin{tabular}{llllll}
\hline Tracer disease & $\begin{array}{l}\text { Diagnostic } \\
\text { procedure }\end{array}$ & \multicolumn{2}{c}{ Health insurance payment methods } & Results \\
\cline { 3 - 5 } & & 30 Baht Scheme (\%) & SSS (\%) & CSMBS (\%) \\
\hline AUGIB & Gastroscope & $22(53.56)$ & $10(55.56)$ & $218(68.55)$ & 0.110 \\
Lung cancer & CT scan/ MRI & $25(59.52)$ & $11(35.48)$ & $194(74.62)$ & 0.000 \\
\hline
\end{tabular}

difference is even greater. New drugs were prescribed to $67 \%$ of CSMBS patients, compared with $19 \%$ and $10 \%$ of 30 Baht and SSS patients, respectively.

Further analysis reveals that of the 15 patients in the 30 Baht group prescribed new antiepileptic drugs, 14 paid for the new drugs out of pocket. Similarly, 9 out of 13 of the SSS group also paid out of pocket. For those covered by the CSMBS, all could get drug costs reimbursed. Prescribing for the new anti-neoplastic drugs follows a similar pattern: 5 out of 8 patients in the 30 Baht Scheme treated with new drugs bought the drugs on their own.

These findings suggest that even among people covered by the same health insurance system, unequal access to new drugs might still exist, depending on whether a patient pays out of pocket.

\section{Palliative drugs}

Almost all lung cancer patients who received chemotherapy had anti-emetics drugs prescribed with no difference among schemes. Approximately 12\% of SSS and CSMBS lung cancer patients were given G-CSF, while none of the 42 patients in the 30 Baht group received the drug, although the difference was not tested significantly.

Additional analysis into whether there was a difference in prescription of originator versus generic products shows a statistically significant difference with much higher percentage of CSMBS beneficiaries (59\%) receiving originator, and thus more expensive, drugs than those in the other two schemes (7\% and 6\%).

\section{High-cost diagnostic procedures}

AUGIB patients in all three health insurance programs had about the same chance of being diagnosed using gastroscopic imaging. By contrast, fewer lung cancer patients in the programs with closed-end payment received an MRI or a CT scan, both high-cost procedures (Table 6).

The price differences of the different types of medical technologies are shown in Tables 7 and 8 . When hospitals are paid on a closed-end basis, it is financially rewarding to restrict access to drugs and services, especially high-cost items. The rationale of service management appears self-explanatory. It also raises the question of how practice patterns affect quality of care.

\section{Efficiency in resource use}

1. AUGIB The cost of medicines used to treat CSMBS patients was the highest among the three groups. Because there was no significant difference in the effectiveness of treatment, its cost-effectiveness for pharmacotherapy was then the lowest among the three. Further analysis was done to gauge the severity of the patient condition, identified 
Table 7 Costs of key drugs in various categories used in the tracer conditions

\begin{tabular}{|c|c|c|c|}
\hline \multirow{3}{*}{$\begin{array}{l}\text { Type of drugs } \\
\text { New versus } \\
\text { conventional drugs }\end{array}$} & \multirow{2}{*}{$\begin{array}{l}\text { Pharmacological group } \\
\text { Anti-epileptic drugs }\end{array}$} & \multicolumn{2}{|c|}{ Drug cost: Baht } \\
\hline & & $\begin{array}{l}\text { New drug lamotrigine } 100 \mathrm{mg} \\
\text { tablet: } 31.49\end{array}$ & $\begin{array}{l}\text { Conventional drug phenytoin } \\
100 \text { mg capsule: } 1.92\end{array}$ \\
\hline & Anti-neoplastic drug & $\begin{array}{l}\text { New drug gemtarabine } 1 \mathrm{gm} \\
\text { inj.: } 8767.58\end{array}$ & $\begin{array}{l}\text { Conventional drug } \\
\text { doxorubicin } 50 \mathrm{mg} \text { inj.: } \\
1047.7\end{array}$ \\
\hline $\begin{array}{l}\text { Required versus other } \\
\text { drugs }\end{array}$ & Alimentary drug & $\begin{array}{l}\text { Required drug omeprazole } \\
20 \text { mg capsule: } 2.46\end{array}$ & $\begin{array}{l}\text { Other drug ranitidine } 150 \mathrm{mg} \\
\text { tablet: } 0.40\end{array}$ \\
\hline Oral versus injection & Alimentary drug & $\begin{array}{l}\text { Oral form omeprazole } 40 \mathrm{mg} \text { : } \\
\quad 331.70\end{array}$ & $\begin{array}{l}\text { Injection form omeprazole } \\
20 \mathrm{mg}: 2.46\end{array}$ \\
\hline \multirow[t]{2}{*}{$\begin{array}{l}\text { Originator versus } \\
\text { generic drugs }\end{array}$} & Alimentary drug & $\begin{array}{l}\text { Originator omeprazole } 20 \mathrm{mg} \\
\text { capsule: } 55.03\end{array}$ & $\begin{array}{l}\text { Generic omeprazole } 20 \mathrm{mg} \\
\text { capsule: } 2.46\end{array}$ \\
\hline & Anti-emetic drugs & $\begin{array}{l}\text { Originator ondansetron } 8 \mathrm{mg} \\
\text { Zydis: } 314.58\end{array}$ & $\begin{array}{l}\text { Generic ondansetron } 8 \mathrm{mg} \\
\text { tablet: } 11.98\end{array}$ \\
\hline \multirow[t]{2}{*}{$\begin{array}{l}\text { Palliative drugs versus } \\
\text { no drug }\end{array}$} & Anti-emetic drugs & $\begin{array}{l}\text { Palliative drug ondansetron } \\
8 \mathrm{mg} \text { : tablet } 11.98\end{array}$ & No drug 0 \\
\hline & G-CSF & $\begin{array}{l}\text { Palliative drug granocyte } 100 \\
\text { mcg: } 1515.83\end{array}$ & No drug 0 \\
\hline
\end{tabular}

Table 8 Hospital charges for diagnostic procedures required in the tracer conditions

\begin{tabular}{lll}
\hline Tracer disease & $\begin{array}{l}\text { Charges for required } \\
\text { diagnostic equipment } \\
\text { (Baht) }\end{array}$ & $\begin{array}{l}\text { Charges for } \\
\text { alternative method } \\
\text { (Baht) }\end{array}$ \\
\hline AUGIB & Gastroscopy & Observe \\
Non-small cell & CT scan & 0 \\
lung cancer & $5000-8000$ & Chest X-ray \\
& MRI & 100 \\
& $8000-15000$ & Chest X-ray \\
& & 100
\end{tabular}

according to relevant clinical criteria. It was found that the majority were serious cases, and cost-effectiveness results still favor the closed-end schemes, as shown in Table 9. Since drugs in the PPI category are therapeutically equivalent - that is, old and new drugs in both oral and injection dosage forms have the same efficacy in inhibiting gastric acid secretion - the use of cheaper drugs (old drugs and oral form) provide more value for the money. But patients with gastrointestinal bleeding often suffer nausea and vomiting. PPI injection has a value in reducing the trouble of swallowing the drug in oral form, which helps lessen patient suffering. The analysis (Table 4) shows that larger percentages of CSMBS patients were prescribed the injection drug than those in the closed-end systems.

2. Epilepsy Drug costs per case were found to be surprisingly close between 30 Baht and CSMBS patients, with the SSS patients costs highest. A significantly larger percentage of CSMBS patients achieved the treatment goal of becoming seizure free. The open-end CSMBS is then the most cost-effective system for this disease condition. 
Table 9 Cost and effectiveness of treating AUGIB cases, classified based on level of clinical risk

\begin{tabular}{llll}
\hline & \multicolumn{2}{c}{ Health insurance payment methods } \\
\cline { 2 - 4 } & \multicolumn{2}{c}{ Closed-end } & Open-end \\
\cline { 2 - 4 } & 30 Baht Scheme & SSS & CSMBS \\
& DRG & Capitation & Fee-for-service \\
\hline Low clinical risk & & & 9 \\
\# of cases & 3 & 4 & $2,036.68$ \\
Cost & 296.97 & 995.03 & $100.00 \%$ \\
Effectiveness & $100.00 \%$ & $100.00 \%$ & 2036.68 \\
C/E ratio & 296.97 & 995.03 & 151 \\
High clinical risk & & & $5,424.21$ \\
\# of cases & 26 & 9 & $96.00 \%$ \\
Cost & $1,958.09$ & $1,855.39$ & 5650.22 \\
Effectiveness & $96.15 \%$ & $100.00 \%$ & 1855.39 \\
C/E ratio & 2036.50 & & \\
\hline
\end{tabular}

3. Non-small cell lung cancer Cancer is a high-cost disease. New generations of anti-neoplastic drugs are available at higher and higher prices. Treatment of 30 Baht and SSS patients for non-small cell lung cancer, with the use of mainly conventional anti-neoplastic rather than new drugs, incurred significantly lower expenses than treatment of CSMBS patients (Tables 4 and 10). The closed-end 30 Baht Scheme yielded the most cost-effective results. But in terms of effectiveness, there were approximately $20 \%$ more success cases in the CSMBS group.

\section{Discussion}

In emergencies involving gastrointestinal bleeding, patients in all insurance schemes received the care required by clinical practice guidelines, with no significant association between the method of provider payment and the required services. In this case, the availability of drugs and equipment at moderate cost might also be beneficial to broad access.

By contrast, utilization of more expensive items differs between the closed- and open-end systems. It seems that where new and conventional drugs are both available with a considerable price gap, patients in a fee-for-service health insurance scheme tend to have greater access to more expensive drugs. This pattern is also evident in cases of originator versus generic drugs, drugs with different dosage forms, and more versus less advanced diagnostic technologies.

What added value do these advanced medical technologies offer? The new anti-epileptics render better control of seizures and have fewer side effects. As a result, 20\% more CSMBS patients became seizure free than those in the closed-end systems. For lung cancer, 20\% more CSMBS patients than those in the closed-end systems were able to live through their next birthday with new generation anti-neoplastics. Note also that almost all patients in the closed-end insurance schemes who took these new drugs paid for their drugs out-of-pocket. With more prescriptions of PPI injections for AUGIB, patients probably enjoy a better quality of life. Unfortunately, this study focused on clinical quality and did not include any measure of quality of life in the analysis. 
Table 10 Drug costs and cost-effectiveness of treatment

\begin{tabular}{|c|c|c|c|c|}
\hline \multirow[t]{3}{*}{ Tracer } & \multirow[t]{3}{*}{ Efficiency in resource use } & \multicolumn{3}{|c|}{ Health insurance payment methods } \\
\hline & & \multicolumn{2}{|c|}{ Closed-end } & \multirow{2}{*}{$\begin{array}{l}\text { Open-end } \\
\text { CSMBS } \\
\text { FFS }\end{array}$} \\
\hline & & $\begin{array}{l}30 \text { Baht Scheme } \\
\text { DRG }\end{array}$ & $\begin{array}{l}\text { SSS } \\
\text { Capitation }\end{array}$ & \\
\hline \multirow{6}{*}{$\begin{array}{l}\text { Acute } \\
\text { upper } \\
\text { gastroin- } \\
\text { testinal } \\
\text { bleeding }\end{array}$} & \# of cases & 29 & 13 & 160 \\
\hline & $\begin{array}{l}\text { Average drug cost (Baht) per } \\
\text { case } \\
p \text { value }\end{array}$ & $\begin{array}{l}1,742.31 \\
0.026\end{array}$ & $1,590.67$ & $4,848.90$ \\
\hline & \# of cured cases & $28(96.55 \%)$ & $13(100.00 \%)$ & $154(96.25)$ \\
\hline & $p$ value & 1.000 & & \\
\hline & $\begin{array}{l}\text { Average drug cost (Baht) per } \\
\text { cured case }\end{array}$ & $1,804.54$ & $1,590.67$ & $5,037.82$ \\
\hline & & Capitation and DRG & Capitation & FFS \\
\hline \multirow[t]{7}{*}{ Epilepsy } & \# of cases & 89 & 62 & 288 \\
\hline & $\begin{array}{l}\text { Average drug cost (Baht) per } \\
\text { case }\end{array}$ & $5,755.96$ & $9,301.13$ & $5,956.56$ \\
\hline & $p$ value & 0.05 & & \\
\hline & \# of seizure free cases & $78(77.23 \%)$ & $49(63.64 \%)$ & $259(90.24 \%)$ \\
\hline & $p$ value & 0.000 & & \\
\hline & $\begin{array}{l}\text { Average drug cost (Baht) per } \\
\text { seizure free case }\end{array}$ & $7,318.29$ & $14,416.76$ & $6,623.55$ \\
\hline & & Per item with ceiling & Per item with ceiling & FFS \\
\hline \multirow{5}{*}{$\begin{array}{l}\text { Non-small } \\
\text { cell lung } \\
\text { cancer } \\
\text { (stage } \\
3-4)\end{array}$} & \# of cases & 17 & 5 & 67 \\
\hline & $\begin{array}{l}\text { Average drug cost (Baht) per } \\
\text { case } \\
p \text { value }\end{array}$ & $\begin{array}{l}47,572.42 \\
0.000\end{array}$ & $60,493.24$ & $160,905.27$ \\
\hline & \# of success case & $7(41.17 \%)$ & $2(40 \%)$ & $41(61.19 \%)$ \\
\hline & $p$ value & 0.317 & & \\
\hline & $\begin{array}{l}\text { Average drug cost (Baht) per } \\
\text { success case }\end{array}$ & $115,533.03$ & $151,233.09$ & $262,942.76$ \\
\hline
\end{tabular}

Regarding the cost-effectiveness of pharmaco-therapy, it was found that average drug costs for treating AUGIB and non-small cell lung cancer were comparable, but there was a significant gap between patients in closed-end systems and those in the CSMBS. Since effectiveness of AUGIB treatment did not differ among the groups, the closed-end programs were more cost-effective than the open-end one. In the treatment of non-small cell lung cancer, care rendered to CSMBS patients was more effective but less efficient due to the high cost of cancer drugs.

In cases of epilepsy, which is a chronic condition, treatment cost more for the closed-end SSS patients but with fewer seizure-free cases than in the CSMBS. In addition, the aver- 
age drug costs for CSMBS patients were about as those for 30 Baht patients. From a more in-depth examination of the medical records, it was found that patients in the closed-end payment schemes often began with conventional drugs. Due to the lower efficacy of the conventional anti-epileptic medicines compared to the new ones, more drug items were then added subsequently for these patients to control seizures. Adding together the costs of the multiple items might be the reason for the higher overall costs. It appears that, in the attempt to save costs, effectiveness and probably quality of life had to be compromised. Nonetheless, we did not conduct in-depth analysis of the medical records on this additional aspect; the point is more suggestive than conclusive.

Considering utilization patterns, available medical technologies, and concerns about costs and effectiveness, a key question arises: How much is a society willing to pay for the health care of its members? Or, more specifically, for what level of effectiveness and quality of life is it willing to pay?

Another point worth pondering is that the analysis of AUGIB shows no difference in the utilization of the required drug, PPI, while in the other two cases, drug utilization patterns differ among groups. Taking into account the emergency nature of diseases like AUGIB and the relatively non-urgent nature of other conditions, does this suggest that factors such as the nature of a disease and its cure might play a role in medical decisions and modify the effects of financial incentives? The common classification systems currently used to determine payment methods are based on crude criteria such as point of service, inpatient versus outpatient, cost of input, and general versus high cost. Perhaps these criteria are better suited to convenient rate calculation than to influencing health care efficiency. Designing better payment methods that will help increase the effectiveness and efficiency of care requires reconceptualization and more research and development.

Open Access This article is distributed under the terms of the Creative Commons Attribution Noncommercial License which permits any noncommercial use, distribution, and reproduction in any medium, provided the original author(s) and source are credited.

\section{References}

Chaix-Couturier, C., Durand-Zaleski, I., Jolly, D., \& Durieux, P. (2000). Effects of financial incentives on medical practice: Results from a systematic review of the literature and methodological issues. International Journal for Quality in Health Care, 12(2), 133-142. doi:10.1093/intqhe/12.2.133.

Epilepsy Society of Thailand, Queen Sirikit National Institute of Child Health, Bureau of Medical Technical Department. (2004). Guidelines of epilepsy. Bangkok: Sahadhmic Co. Ltd.

Gastroenterological Association of Thailand. (2004). Clinical practice guidelines for the management of UGIB. Bangkok: Union Creation.

Jegers, M., Kestellot, K., Grave, D., Grilles, W. (2002). A typology for provider payment systems in health care. Journal of Health Policy, 60, 255-273.

Krejcie, R. V., \& Morgan, D. W. (1970). Determining sample size for research activities. Journal of Educational and Psychological Measurement, 30(3), 607-610.

McCall, N., Korb, J., Petersons, A., \& Moore, S. (2003). Reforming medicare payment: Early effects of the 1997 Balanced Budget Act on postacute care. Journal of Milbank Quarterly, 81(2), 277-303. doi:10.1111/ 1468-0009.t01-1-00054.

National Cancer of Thailand and Department of Medical Service. (2005). Guidelines of lung cancer treatment. Bangkok: Ministry of Public Health.

National Statistics Bureau. (2007). Health and welfare survey: Summary of preliminary results. http://service. nso.go.th/nso/nsopublish/service/survey/sum_health_50.pdf. Accessed 15 May 2008.

Petersen, L. A., Woodard, L. D., Urech, T., Daw, C., \& Sookanan, S. (2006). Does pay-for-performance improve the quality of health care? Annals of Internal Medicine, 145(4), 265-272.

Ratanawijitrasin, S. (2005). Health insurance: An in-depth guide. Bangkok: Chulalongkorn University Press. 